\title{
Effect of a patient-specific minimum activity in stress myocardial perfusion imaging using CZT- SPECT: Prognostic value, radiation dose, and scan outcome
}

\author{
J. D. van Dijk, MSc, PhD (1), ${ }^{\mathrm{a}, \mathrm{d}}$ N. M. Borren, MD, ${ }^{\mathrm{b}}$ M. Mouden, MD, PhD, ${ }^{\mathrm{b}}$ \\ J. A. van Dalen, PhD, ${ }^{c}$ J. P. Ottervanger, $M D, P h D,{ }^{b}$ and P. L. Jager, $M D, P h D^{a}$ \\ a Department of Nuclear Medicine, Isala Hospital, Zwolle, The Netherlands \\ ${ }^{b}$ Department of Cardiology, Isala Hospital, Zwolle, The Netherlands \\ c Department of Medical Physics, Isala Hospital, Zwolle, The Netherlands \\ ${ }^{d}$ MIRA: Institute for Biomedical Technology and Technical Medicine, University of Twente, \\ Enschede, The Netherlands
}

Received Apr 19, 2017; accepted May 31, 2017

doi: $10.1007 / \mathrm{s} 12350-017-1011-\mathrm{z}$

Background. SPECT Myocardial perfusion imaging (MPI) is associated with a relatively high radiation burden and decreasing image quality in heavy patients. Patient-specific low-activity protocols (PLAPs) are suggested but follow-up data is lacking. Our aim was to compare the use of a standard fixed-activity protocol (FAP) with a PLAP in cadmium zinc telluride (CZT)-SPECT MPI.

Methods. We retrospectively included 1255 consecutive patients who underwent CZTSPECT stress-optional rest MPI. 668 Patients were scanned using FAP (370 MBq) and 587 patients using PLAP (2.25 MBq $\left.\mathrm{kg}^{-1}\right)$. Percentage of scans interpreted as normal, radiation dose, and 1-year follow-up including hard event rates (all-cause death or non-fatal myocardial infarction) were collected and compared.

Results. The percentage of scans interpreted as normal was $67 \%$ in FAP and $70 \%$ in PLAP groups $(P=.29)$. The annualized hard event rates in these patients were $1.0 \%$ in the FAP and $0.9 \%$ in the PLAP group $(P=.86)$. However, the mean radiation dose decreased by $23 \%$ for stress-only and by $15 \%$ to $2.6 \mathrm{mSv}$ for stress-optional rest MPI after introduction of the PLAP $(\mathbf{p}<0.001)$.

Conclusions. Introduction of a patient-specific low-activity protocol does not affect the percentage of scans interpreted as normal or prognosis but significantly lowers the radiation dose for CZT-SPECT MPI. (J Nucl Cardiol 2018;25:26-35.)

\section{Spanish Abstract}

Antecedentes. El estudio de imagen de perfusión miocárdica con SPECT (MPI, por sus siglas en ingles) se asocia con una carga de radiación relativamente alta y una menor calidad de

\section{See related editorial, pp. 36-38}

Electronic supplementary material The online version of this article (doi:10.1007/s12350-017-1011-z) contains supplementary material, which is available to authorized users.

The authors of this article have provided a PowerPoint file, available for download at SpringerLink, which summarizes the contents of the paper and is free for re-use at meetings and presentations. Search for the article DOI on SpringerLink.com.

JNC thanks Erick Alexanderson MD, Carlos Guitar MD, and Diego Vences MD, UNAM, Mexico, for providing the Spanish abstract; Haipeng Tang MS, Zhixin Jiang MD, and Weihua Zhou PhD, for providing the Chinese abstract; and Jean-Luc Urbain, MD, PhD, CPE, Past President CANM, Chief Nuclear Medicine, Lebanon VAMC, PA, for providing the French abstract.

Reprint requests: J. D. van Dijk, MSc, PhD, Department of Nuclear Medicine, Isala Hospital, PO Box 10400, 8000 GK Zwolle, The Netherlands; jorisvdijk@gmail.com $1071-3581 / \$ 34.00$

Copyright (C) 2017 The Author(s). This article is an open access publication 
imagen en pacientes obesos. Se sugieren protocolos de baja actividad específica para cada pacientes (PBAP), sin embargo faltan datos de seguimiento. Nuestro objetivo fue comparar el uso de un protocolo con actividad fija estándar (PAF) con un PBAP en un estudio de perfusión miocárdica con SPECT CZT cadmio-zinc-telurio.

Métodos. Incluimos de manera retrospectiva 1255 pacientes consecutivos que se sometieron a un SPECT CZT de estrés con fase de reposo de manera opcional. 668 pacientes fueron escaneados usando un PAF (370 MBq) y 587 pacientes utilizando un PBAP (2.25 MBq/kg). Los porcentajes de exploraciones interpretadas como normales, dosis de radiación y seguimiento de un año incluyendo tasas de eventos duros (muerte por todas las causas o infarto de miocardio no fatal) fueron recolectados y comparados.

Resultados. El porcentaje de exploraciones interpretadas como normales fue de $67 \%$ en el PAF y de 70\% en el PBAP $(p=0.29)$. Las tasas de eventos duros anuales en estos pacientes fueron del $1.0 \%$ en el PAF y del $0.9 \%$ en el PBAP $(p=0.86)$. Sin embargo, la dosis de radiación media disminuyó en un $23 \%$ para los estudios de solo estrés y en un $15 \%$ para $2.6 \mathrm{mSv}$ en el estudio de estrés con reposo opcional después de la introducción del PBAP (p <0,001).

Conclusiones. La introducción de un protocolo de baja actividad específica para el paciente no afecta el porcentaje de estudios interpretados como normal o el pronóstico, sin embargo reduce significativamente la dosis de radiación para el SPECT CZT. (J Nucl Cardiol 2018;25:26-35.)

\section{Chinese Abstract}

背景. 肥胖病人进行 SPECT 心肌灌注成像 (MPI) 时,会接受较高的辐射量, 并且图像质量 也会降低。因而建议病人采用个体化低剂量方案 (PLAPs), 但目前尚缺乏随访数据。我们的 研究在于利用铬锌镝晶体探头 (CTZ)-SPECT MPI, 比较标准化剂量方案 (FAP) 和个体化低 剂量方案 PLAP 的优劣。

方法. 我们回顾性的纳入1255 名都进行了CTZ-SPECT 负荷可选-静息 MPI 的连续病 人。668 名病人采用 FAP (370 MBq) 扫描, 587 名病人采用 PLAP $(2.25 \mathrm{MBq} / \mathrm{kg})$ 扫描。观察 比较两组间的扫描正常比率、辐射剂量和一年随访的硬终点事件发生率(包括全因死亡或非致 命性心肌梗死)。

结果. 在 FAP 组, 扫描正常的百分比为 67\%; 在 PLAP 组为 70\% $(p=0.29)$ 。 FAP 组年硬 终点事件发生率为 $1.0 \%$, PLAP 组为 $0.9(\mathrm{p}=0.86)$ 。然而, PLAP 组单纯负荷 MPI 的平均辐射剂 量减少 $23 \%$, 负荷可选-静息 MPI 则减小 $15 \%$, 达 $2.6 \mathrm{mSv}(\mathrm{p}<0.001)$ 。

结论. 对于 CTZ-SPECT MPI, PLAP 方案不影响扫描正常的比率和预后, 但会显著降低辐 射剂量。(J Nucl Cardiol 2018;25:26-35.)

\section{French Abstract}

Contexte. Les examens tomographiques et scintigraphiques (SPECT) de la perfusion myocardique chez les patients obèses sont généralement associées à des études sub-optimales et à une exposition non négligeable aux radiation ionisantes. Des études utilisant des doses réduites de matériel radioactif ont été proposées chez ces patients. Néanmoins les résultats de ce genre d'études publiés dans la littérature sont relativement rares. L'objectif de cette étude était de comparer les résultats des examens obtenus avec des doses conventionnelles avec ceux obtenus avec la nouvelle génération de gamma cameras équipées de detectors de Cadmium-Zinc Telluride (CZT) et des doses ajustées en fonction du poids des patients.

Méthodes. Pour cette étude rétrospective, nous avons inclus 1255 patients consécutifs qui ont beneficiés d'un examen scintigraphique après épreuve d'effort pharmacologique et, au besoin, d'un examen complémentaire de repos. Les patients (668) ont été étudies après l'injection standard de $370 \mathrm{MBq}$ (dose conventionnelle) et 587 patients ont été étudiés après l'injection de $2,25 \mathrm{MBq} \cdot \mathrm{kg}^{-1}$ (dose réduite). Le pourcentage d'examens scintigraphiques normaux, les doses de radiation et le suivi clinique des patients pendant un an (décès ou infarctus myocardique) et ont été revus et analysés.

Résultats. Le pourcentage d'examens normaux fut calculé a $67 \%$ dans le groupe de patients injectés avec doses conventionnelles et à $70 \%$ dans le groupe injecté avec des doses réduites $(p=$ 
0,29). Les taux d'événements cliniques subséquents et significatifs fut de $1,0 \%$ dans le premier groupe et de $0,9 \%$ dans le second groupe $(p=0,86)$. Néanmoins, le pourcentage de radiation chez les patients étudiés uniquement à l'effort fut de $23 \%$ inferieur. Après examen à l'effort et au repos, la dose moyenne de radiation diminua de $15 \%$ en utilisant les doses adaptées au poids $(p<0,001)$.

Conclusions. les examens réalisés avec des doses réduites de matériel radioactif et la nouvelle génération de gamma camera utilisant les detectors semi solide CZT ne modifie pas pas le pourcentage d'examens interprétés comme normaux ni le pronostique des patients mais diminue de manière significative l'exposition aux radiations ionisantes. (J Nucl Cardiol 2018;25:26-35.)

Key Words: Radiation dose reduction $\cdot$ stress-only $\cdot$ myocardial perfusion imaging:

SPECT $\cdot$ CdZnTe $\cdot$ High-efficiency camera

\begin{tabular}{|ll|}
\hline Abbreviations \\
BMI & Body mass index \\
CT & Computer tomography \\
CZT & Cadmium zinc telluride \\
FAP & Fixed-activity protocol \\
PAST & Product of tracer activity and scan time \\
PLAP & Patient-specific low-activity protocol \\
MPI & Myocardial perfusion imaging \\
SPECT & $\begin{array}{l}\text { Single photon emission computed } \\
\text { tomography }\end{array}$ \\
&
\end{tabular}

\section{INTRODUCTION}

Single photon emission computed tomography (SPECT) myocardial perfusion imaging (MPI) is the most validated non-invasive method to test for ischemia in patients with known or suspected of coronary artery disease. ${ }^{1,2}$ Although SPECT MPI is widely used, it is also associated with a relatively high radiation dose, contributing to approximately $10 \%$ of the cumulative radiation dose of medical procedures in the United States. ${ }^{3}$

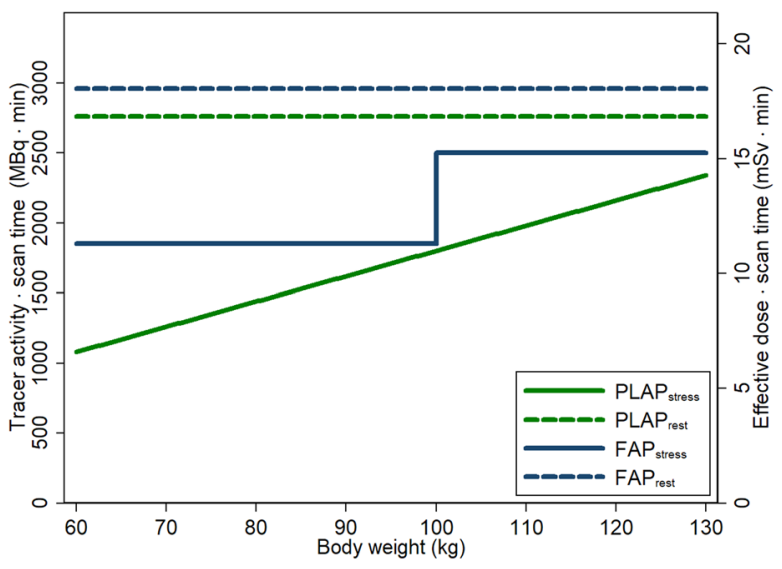

Figure 1. Line graph demonstrating the product of tracer activity and scan time (PAST) for the fixed-activity protocol (FAP) and patient-specific low-activity protocol (PLAP). The solid lines represent the PAST for stress MPI and the dashed lines represent the PAST for rest MPI. The secondary $y$-axis shows the product of the effective patient dose and scan time.
Multiple attempts have been made to reduce the high dose associated with SPECT MPI. Introduction of stress-only protocols reduced the radiation dose by $63 \%$ without reducing its prognostic value. ${ }^{4}$ Moreover, applying attenuation correction can further reduce this dose by an additional $16 \%$ due to an increase in normalcy rate and lower need for additional rest imaging. ${ }^{5-7}$ In addition, multiple studies showed that the introduction of a new generation cadmium zinc telluride (CZT)-based SPECT cameras allows further dose reductions. ${ }^{8-10}$ However, these studies did not determine the minimal product of tracer activity and scan time (PAST) that does not affect the diagnostic outcome in CZT-SPECT MPI. In our previous studies, we demonstrated that a body-weight dependent activity protocol not only resulted in an improved image quality but also in the possibility to further lower the tracer activity. ${ }^{11,12}$ Prognostic evidence that such a low bodyweight dependent activity protocol with limited scan time does not affect diagnostic outcome is lacking. Hence, our aim was to compare the standard fixedactivity protocol (FAP) and patient-specific low-activity protocol (PLAP) with regard to percentage of scans interpreted as normal, radiation dose, and prognostic value for CZT-SPECT MPI.

\section{MATERIALS AND METHODS}

\section{Patient Population}

Patients who underwent clinically indicated CZTSPECT/computer tomography (CT) same-day stress-optional rest MPI (Discovery NM 570c, GE Healthcare) between February and June 2013 or between June and October 2014 were retrospectively included. All patients had a low to intermediate pre-test likelihood without a history of coronary artery disease. Patients included in the first period received a fixed activity. Based on the outcomes of our previous studies, ${ }^{11,13}$ we changed our clinical protocol, as shown in Figure 1. Patients included in the second group received a patient-specific activity.

This study was retrospective and as all patients received the best clinical protocol available at the time of scanning, 
formal informed consent or approval by the medical ethics committee was not required. Subjects did provide written informed consent for the use of data for research purposes and the active collection of follow-up data in accordance with the Dutch Privacy laws.

\section{Clinical Information}

At the time of examination, all patients completed a questionnaire regarding demographic information, prior medical history, cardiac risk factors, and current medication use. These data were verified and complemented with demographic and clinical information collected from medical records.

\section{Patient Preparation and Image Acquisition}

Patients were instructed to refrain from caffeine-containing beverages for $24 \mathrm{~h}$. Pharmacological stress was induced by intravenous adenosine $\left(140 \mu \mathrm{g} \cdot(\mathrm{kg} \cdot \text { minute })^{-1}\right.$ for 6 minutes $)$ or dobutamine $\left(10 \mu \mathrm{g} \cdot(\mathrm{kg} \text { minute })^{-1}\right.$ increased to a maximum of $50 \mu \mathrm{g} \cdot(\mathrm{kg} \cdot \mathrm{minute})^{-1}$ until $85 \%$ of the predicted maximum heart rate was reached). Pharmacologic stress was used solely due to logistic reasons, in particular, the high patient throughput in our center. ${ }^{14}$ All patients were injected intravenously at peak stress with an activity of Tc-99m Tetrofosmin which varied between both groups. Patients in the FAP group received a fixed activity of $370 \mathrm{MBq}$ or $(500 \mathrm{MBq}$ for patients weighing more than $100 \mathrm{~kg}$ ). When the stress images were not interpreted as normal, and rest imaging was clinically indicated, patients received a fixed activity of $740 \mathrm{MBq}$ Tc-99m Tetrofosmin intravenously at least 3 hours after the stress activity administration. Patients in the PLAP group received a weight adjusted activity of $2.25 \mathrm{MBq} \cdot \mathrm{kg}^{-1}$ prior to stress acquisition. ${ }^{13}$ A fixed activity of $460 \mathrm{MBq}$ was administered at least 3 hours post stress injection when rest imaging was clinically indicated.

Electrocardiographically-gated SPECT acquisition was performed 60 minutes post injection with the patient in supine position with arms placed above their head. Prior to scanning, the patient's heart was positioned in the center of the CZTSPECT scanner using real-time persistence imaging. Stress scans were acquired during 5 minutes in the FAP group and 8 minutes in the PLAP group using a $20 \%$ symmetrical energy window centered at $140 \mathrm{keV}$. Rest scans were acquired using scan times of 4 minutes in the FAP group and 6 minutes in the PLAP group. As longer scan times were used in the PLAP group, this automatically lowered the required activity. ${ }^{15} \mathrm{We}$ therefore did not only compare the administered activity between both protocols but also the PAST, as this metric accounts for changes in both activity and scan time. Patients in the PLAP group received a $25 \%$ lower PAST during stress MPI. This lower PAST was achieved by lowering the activity by $53 \%$ while prolonging the scan time by $38 \%$. The PAST for rest MPI was lowered by $7 \%$ by lowering the activity by $38 \%$ and prolonging the scan time by $33 \%$.

After either the stress or rest SPECT acquisitions, an unenhanced low-dose CT-scans during breath-hold was made to provide an attention map of the chest (LightSpeed VCT XT; GE Healthcare). These scans were made using a $5.0 \mathrm{~mm}$ slice thickness, $800 \mathrm{~ms}$ rotation time, pitch of 1.0 , collimation $64 \times 0.625 \mathrm{~mm}$, tube voltage of $120 \mathrm{kV}$, tube current of $10 \mathrm{~mA}$, and a mean irradiated body length of $24.4 \mathrm{~cm}$. In addition, a coronary artery calcification (CAC)-CT scan was made. This scan was triggered at $75 \%$ of the R-R interval a $2.5 \mathrm{~mm}$ slice thickness, $330 \mathrm{~ms}$ rotation time, pitch of 1.0, collimation $64 \times 0.625 \mathrm{~mm}$, tube voltage of $120 \mathrm{kV}$, and a tube current varying between 125 and $250 \mathrm{~mA}$ using 40 or 48 sections.

Subsequently, SPECT data were reconstructed using a dedicated reconstruction algorithm (Myovation, GE Healthcare) with and without CT-based attenuation correction and displayed in the traditional short, vertical long and horizontal long axes. Moreover, post-processing of the CAC-scans was performed using dedicated software (SmartScore, Advantage Windows 4.4, GE Healthcare) to determine the CAC score using the Agatston criteria. ${ }^{16}$ The average radiation dose from the Tc-99m activity was calculated for the stress-only and stress-optional rest scans and corrected for the longer scan time. Conversion factors of $5.8 \times 10^{-3}$ and $6.3 \times 10^{-3} \mathrm{mSv} \cdot \mathrm{MBq}^{-1}$ were used to estimate the effective dose for stress and rest MPI, respectively. ${ }^{17}$ The radiation dose associated with the CAC score $(0.9 \mathrm{mSv})$ and attenuation correction $(0.29 \mathrm{mSv})$ CT-scans were not included in the further analysis as they were identical for both groups.

\section{Clinical Interpretation}

Perfusion images were interpreted semiquantitatively using the 17 -segment model as part of the clinical routine. ${ }^{18}$ Each segment was scored by consensus of two experienced nuclear cardiology observers using a 5-point scale: $0=$ normal, $1=$ equivocal, $2=$ moderate, $3=$ severe reduction of radioisotope uptake, $4=$ absence of detectable tracer uptake. The attenuation corrected and non-attenuation corrected images, the CAC score and gated SPECT analysis were reviewed and rest SPECT was acquired if there was uncertainty about normalcy of perfusion and if the summed stress score was $>3 .{ }^{18}$ After both stress and rest SPECT, the perfusion images were reviewed again by a cardiologist and a nuclear physician. An ischemic defect was defined as a summed difference score $\geq 2$. $^{18}$ Perfusion defects which demonstrated no reversibility were defined as fixed defects.

\section{Clinical Follow-Up}

We recorded 1-year follow-up information of all patients by reviewing hospital records and performing scripted telephone interviews with patients. Two follow-up endpoints were defined, (1) the occurrence of hard events, defined as all-cause death or non-fatal myocardial infarction and (2) occurrence of hard cardiac events, defined as cardiac or unknown death or non-fatal myocardial infarction. Non-fatal myocardial infarction was defined based on the criteria of typical chest pain, elevated cardiac enzyme levels, and typical changes on the 
Table 1. Baseline characteristics and scan outcome of all 1255 patients who underwent clinically indicated MPI CZT-SPECT

\begin{tabular}{llll}
\hline \multicolumn{1}{c}{ Characteristic } & $\begin{array}{c}\text { Group FAP } \\
(\mathbf{n}=\mathbf{6 6 8})\end{array}$ & $\begin{array}{c}\text { Group PLAP } \\
(\mathbf{n}=\mathbf{5 8 7})\end{array}$ & $\begin{array}{c}\text { P value }\left(\chi^{\mathbf{2} / \boldsymbol{t}}\right. \\
\text { test) }\end{array}$ \\
\hline Age (years) & $64.6 \pm 11.6$ & $65.5 \pm 11.3$ & 0.17 \\
Male gender & $337(50)$ & $299(51)$ & 0.84 \\
Body weight & $81.8 \pm 15.9$ & $82.3 \pm 15.8$ & 0.57 \\
BMI & $27.5 \pm 4.6$ & $27.6 \pm 4.8$ & 0.84 \\
Current smoking & $99(15)$ & $86(15)$ & 0.56 \\
Hypertension & $419(63)$ & $353(60)$ & 0.38 \\
Diabetes & $132(20)$ & $117(20)$ & 0.96 \\
Dyslipidemia & $308(46)$ & $270(46)$ & 0.98 \\
Family history & $393(59)$ & $318(54)$ & 0.11 \\
Normal MPI scan after stress-only & $293(44)$ & $264(45)$ & 0.69 \\
Normal MPI scan after stress-optional & $448(67)$ & $410(70)$ & 0.29 \\
$\quad$ rest & $122(18)$ & & \\
Ischemic defect & $146(22)$ & $118(20)$ & 0.41 \\
Irreversible defect & $47[0-390]$ & $71(16)$ & 0.004 \\
CAC score & & $71[0-467]$ & 0.37 \\
\hline
\end{tabular}

Patients in the FAP group received a high fixed activity and in the PLAP group a low body-weight dependent activity. $B M I$, Body mass index; $C A C$, coronary artery calcification; values are presented as mean $\pm \mathrm{SD}$, median [25th-75th percentile] or numbers (percentage).
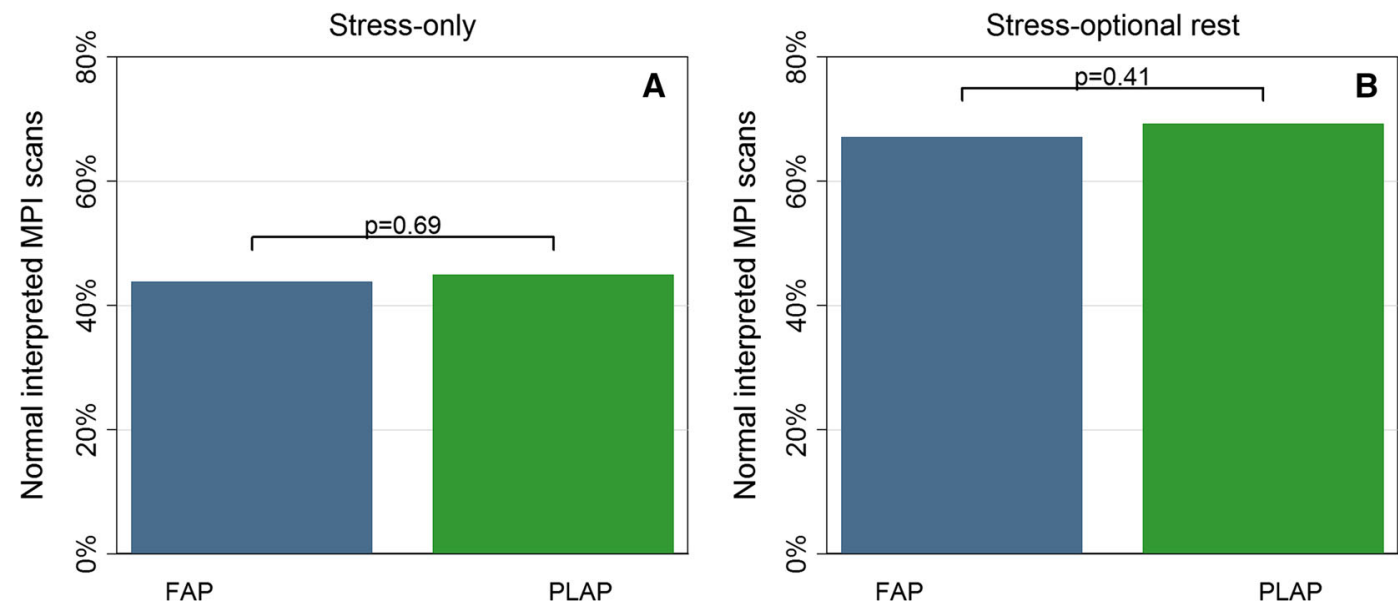

Figure 2. Bar chart showing the percentage of scan interpreted as normal for both the fixed-activity protocol (FAP) and patient-specific low-activity protocol (PLAP) after (A) stress-only and (B) stress-optional rest imaging.

ECG as defined by Thygesen et al. ${ }^{19}$ Data were censored at the first event.

\section{Statistics}

All patient-specific parameters and characteristics were presented as percentages, mean \pm standard deviation (SD) or median and interquartile range and compared using the Chi- square, $t$ test or Mann-Whitney $U$ test when appropriate, using Stata software (StataSE 12.0). The percentage of stress-only scans, percentage of stress-optional rest scans interpreted as normal, administered activity and PAST were compared between the FAP and PLAP group using a Chi-square or a $t$ test. The annualized event-free survival rates for scans interpreted as normal after stress-only or stress-optional rest were analyzed using Kaplan-Meier analysis and compared between 
the FAP and PLAP group using the log-rank test. The level of statistical significance was set to 0.05 (two-sided) for all statistical analyses.

\section{RESULTS}

A total of 1255 patients were included in this study. The study population consisted of 587 patients who underwent MPI using FAP and 668 patients who underwent MPI using the body-weight dependent PLAP. Both groups did not differ regarding age,

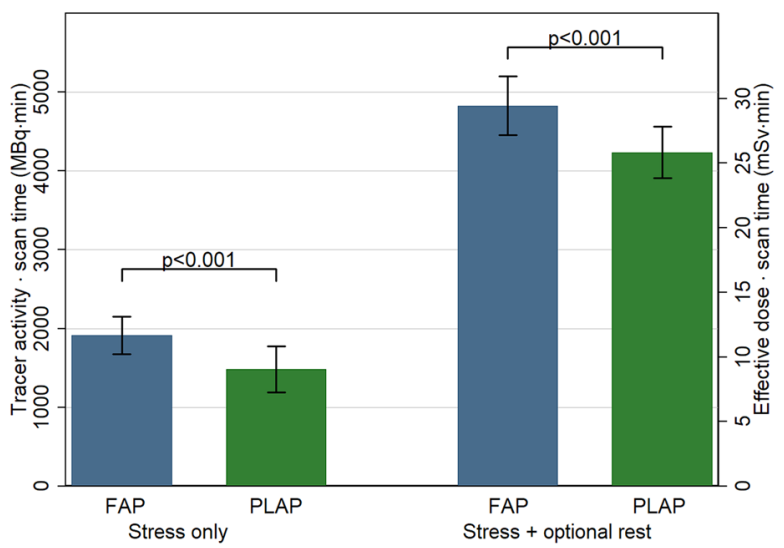

Figure 3. Bar chart showing the mean administered tracer activity multiplied by scan time (PAST) of the fixed (FAP) and patient-specific low-activity protocol (PLAP) for the stressonly imaging and stress-optional rest imaging protocols. The product of tracer and scan time decreased with $23 \%$ for stressonly imaging and $15 \%$ for stress-optional rest imaging $(P<.001)$. gender, body weight, body mass index (BMI), and cardiac risk factors. All baseline characteristics are summarized in Table 1.

\section{Imaging Findings}

The percentage of images interpreted as normal after stress-only imaging did not differ between the FAP and PLAP groups and was $43.9 \%$ and $45.0 \%$, respectively $(P=.69)$, as shown in Figure 2 . The other 698 patients $(55.6 \%)$ also underwent rest imaging. The percentage of scans interpreted as normal in all patients was $67.1 \%$ in the FAP and $69.9 \%$ in the PLAP group $(P=.29)$. The percentage of scans interpreted as having ischemic defects did not differ between the two protocols and was $18.3 \%$ for the FAP and $20.1 \%$ for the PLAP group $(P=.41)$. However, the percentage of scans interpreted as having irreversible defects decreased from $21.9 \%$ in the FAP to $15.5 \%$ in the PLAP group $(P=.004)$.

\section{Past and Radiation Dose}

The mean administered Tc-99m Tetrofosmin activity for stress-only MPI decreased by $52 \%$ after introduction of the new PLAP from $383 \pm 48 \mathrm{MBq}$ $(2.2 \mathrm{mSv})$ to $185 \pm 37 \mathrm{MBq}(1.1 \mathrm{mSv}, P<.001)$. This decrease was $23 \%$ when comparing the PAST (from 1916 to $1482 \mathrm{MBq} \cdot$ minute, $P<.001$ ), as shown in Figure 3.

The mean activity for rest MPI decreased by $38 \%$ from $723 \pm 60 \mathrm{MBq}(4.2 \mathrm{mSv})$ to $452 \pm 31 \mathrm{MBq}$ (2.6 $\mathrm{mSv}, P<0.001)$. The mean PAST for rest MPI decreased by $6 \%$ from 2892 to $2714 \mathrm{MBq} \cdot$ minute
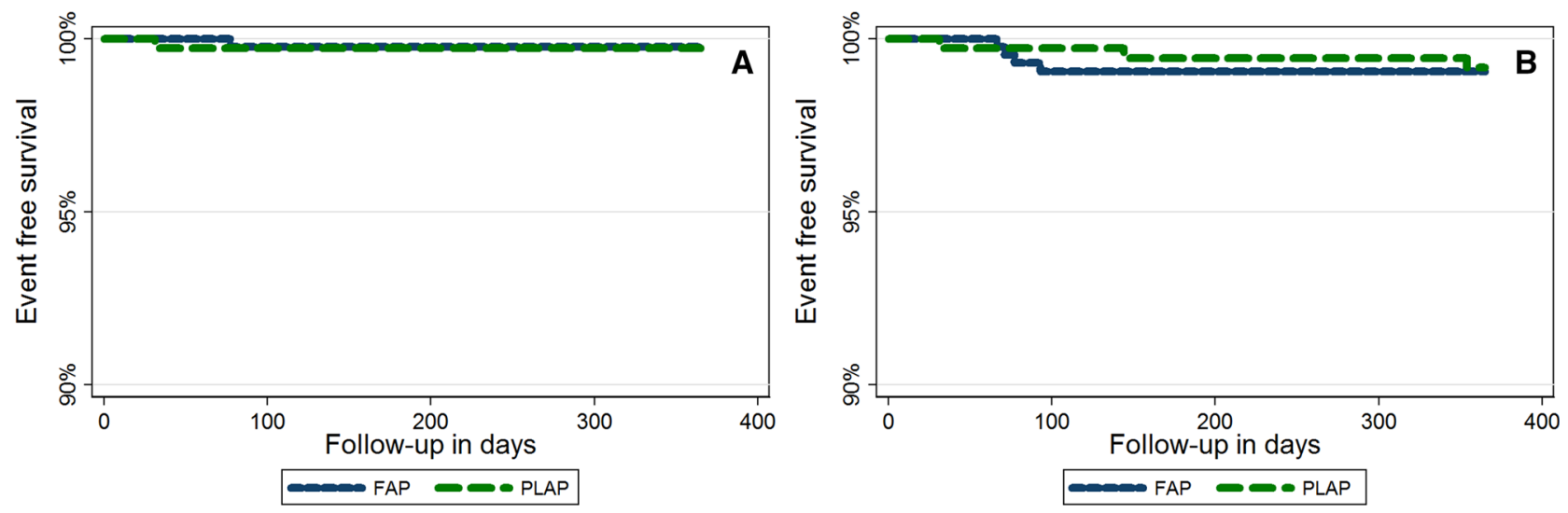

Figure 4. Kaplan-Meier curves of event-free survival of (A) cardiac or unknown death or non-fatal myocardial infarction of scans interpreted as normal and (B) all-cause death or non-fatal myocardial infarction of scans interpreted as normal. Event-free survival rates did not differ significantly between the fixed-activity protocol (FAP) or patient-specific low-activity protocol (PLAP) $(P>.86)$. 
$(P<.001)$. Overall, the mean administered activity during stress-optional rest imaging decreased by $45 \%$ from $789 \pm 369 \mathrm{MBq}(4.8 \mathrm{mSv})$ using the FAP to $435 \pm 234 \mathrm{MBq}(2.6 \mathrm{mSv})$ using the PLAP $(P<.001)$. When correcting for the longer scan times by comparing the PAST, the overall mean effective radiation dose reduction for stress-optional rest imaging was 15\% $(P<.001)$, as shown in Figure 3.

\section{Clinical Follow-Up}

One year follow-up was obtained in 1148 (91.5\%) patients, of whom $634(94.9 \%)$ in the FAP and 514 $(87.6 \%)$ in the PLAP group. Patients in whom followup could not be obtained were excluded from further analysis. Nine patients $(0.8 \%)$, four $(0.6 \%)$ in the FAP and five $(1.0 \%)$ in the PLAP group experienced a nonfatal acute myocardial infarction requiring a primary percutaneous intervention during follow-up. Eight other patients $(0.7 \%)$, four in each group, died during 1-year follow-up. In the FAP group, one died from a cardiac cause and three from a non-cardiac cause. In the PLAP group, all four patients died from a non-cardiac cause.

The annualized hard event rates, the first follow-up endpoint, for the scans interpreted as normal after stressoptional rest were $1.0 \%(4 / 428)$ for the FAP and $0.9 \%$ (3/361) for the PLAP group, as shown in Figure 4. This was a non-statistically significant difference $(P=.86)$. The hard event rates for stress-only scans interpreted as normal were $1.5 \%$ (4/279) for the FAP and $0.9 \%(2 / 233)$ for the PLAP group. This difference was also not significant $(P=.53)$. The second follow-up endpoint, the annualized hard cardiac event rates, for the scans interpreted as normal after stress-optional rest MPI were $0.2 \%(1 / 428)$ for the FAP and $0.3 \%(1 / 361)$ for the PLAP group and did not differ significantly $(P=.91)$. The annualized hard cardiac event rates for the scans interpreted as normal after stress-only MPI were $0.4 \%$ $(1 / 279)$ for the FAP and $0.4 \%$ (1/233) for the PLAP group, also a non-significant difference $(P=.90)$.

\section{DISCUSSION}

In this study, we have demonstrated that introduction of a patient-specific low-activity protocol (PLAP) led to a $23 \%$ reduction in radiation dose in stress CZTSPECT MPI in comparison to the standard fixed-activity protocol (FAP). Nevertheless, the percentages of scans interpreted as normal did not differ between both groups and the prognostic value of these scans did also not differ between the two groups.

Since the introduction of dedicated cardiac CZTbased SPECT cameras, multiple studies were performed on the derivation and evaluation of various imaging protocols with regard to low activity and acquisition times. ${ }^{10,13,20-27}$ However, only a few studies systematically derived the minimal tracer activity or scan time for these cameras. ${ }^{10,21-23}$ Prognostic data of these minimal activity or scan-time protocols is lacking. Moreover, as some studies used extra-long scan times to further minimize the radiation activity, protocols should only be compared using the product of tracer activity and scan time (PAST).

A comparison between the PAST reported by different studies and our PLAP has been described in detail in our previous study. ${ }^{13}$ In short, multiple studies derived PAST protocols with a lower PLAP than used in the present study. ${ }^{10,22,23}$ However, in one study they did not assess possible changes in clinical outcomes or image quality $^{22}$ and the other two studies were only aimed to achieve the same image quality as achieved using conventional protocols. ${ }^{10,23}$ Moreover, CZT-based SPECT cameras are associated with a higher diagnostic value and image quality which might not be achieved when using these low PAST protocols. ${ }^{14,21}$ In addition, Einstein et al showed in a multicenter study that using their protocol resulted in excellent outcomes. ${ }^{21}$ However, they did not determine a minimum PAST and their PAST of $1690 \mathrm{MBq} \cdot$ minute was higher for an average patient of $80 \mathrm{~kg}$ than our PAST of $1440 \mathrm{MBq} \cdot$ minute. Another study by Einstein et al reported an excellent prognostic value of stress-only imaging using a low-activity protocol as they did not encounter any hard cardiac events after 1 year of follow-up. ${ }^{28}$ However, they only included 69 patients and used a PAST of $2775 \mathrm{MBq} \cdot$ minute by using scan times of 15 minutes which is extraordinary long when using a CZT-based SPECT camera.

The cardiac event rates as encountered in our present study are comparable to those as encountered in previous large studies for normally interpreted CZT-SPECT MPI scans. A recent study by Songy et al assessed the prognostic value of a low-activity protocol in stress-only CZT-SPECT imaging with a follow-up of 38.4 months. ${ }^{29}$ They reported annualized cardiac event rates including revascularization of $0.55 \%$ in 1400 patients with a scan interpreted as normal using a PAST $18.5 \mathrm{MBq} \cdot \mathrm{min}-$ ute $\cdot \mathrm{kg}^{-1}$. This is higher than the hard cardiac event rates we encountered using a comparable PAST of 18.0 MBq.minute $\cdot \mathrm{kg}^{-1}$, but we did not include revascularizations. In addition, Chowdhury et al described the prognostic data of CZT-based SPECT MPI in 830 patients with normally interpreted scans with a mean follow-up of 1.7 years. ${ }^{30}$ They reported annualized hard cardiac event rates of $0.2 \%$, which is comparable to the annualized hard cardiac event rates of $0.2-0.3 \%$ as we encountered. However, they used a PAST of $2951 \mathrm{MBq} \cdot$ minute, which is more than two times as high as our PLAP using the same CZT-SPECT camera. 
Yokota et al. reported in a recent study hard cardiac event rates of $0.28 \%$ per annum in 1288 patients who had a normal stress-only CZT-SPECT MPI scan. ${ }^{31}$ They used the same protocol as the FAP in the present study. In addition to the few CZT-SPECT cohort studies, there are multiple large cohort studies describing the prognostic value of a normally interpreted SPECT MPI. They report annual hard cardiac event rates varying between 0.6 and $1.3 \%$ for normally interpreted stress-only scans and between 1.2 and $1.4 \%$ for normally interpreted stress-rest scans. ${ }^{32-35}$ These rates seem slightly higher than encountered in the present study which could be due to differences in the pre-test likelihood and the use of conventional instead of CZT-based SPECT cameras.

Several limitations of this study should be recognized. First, we used a retrospective design. We tried to minimize this influence by the consecutive inclusion of a large number of patients. In addition, although patients from the two groups were scanned in different time periods, acquisition, and reconstruction protocols were identical in both periods except for those mentioned in this study. Nevertheless, the percentage of scans interpreted as having irreversible defects was lower in the PLAP group without any identifiable cause. Secondly, follow-up was not obtained in all patients. Although all deaths are registered in the hospital records, these patients may have encountered a non-fatal myocardial infarction. We cannot exclude the possibility that this may have altered the event rates. Third, the low event rates in this study make the follow-up outcomes susceptible for statistic variation. However, we expect this influence to be limited as the encountered event rates are similar to previous follow-up studies with similar patient groups and larger cohorts. Fourth, the reduction in radiation dose was not solely due to the introduction of the PLAP but also due to longer scan times. However, as activity and scan time are interchangeable up to a certain range, ${ }^{15}$ using the PAST allowed us to determine the radiation dose corrected for longer scan times. Moreover, the maximum scan time of 8 minutes also ensured not to induce additional motion artifacts. ${ }^{36}$ Fifth, the reduction in radiation dose for stress MPI was higher than for rest MPI. The PAST for rest MPI was only lowered by $6 \%$ in contrast to $23 \%$ for stress MPI. This smaller reduction was due to the use of a fixed-activity protocol in our clinic for both the FAP and PLAP groups, as ordering patient-specific rest activity syringes was not possible due to logistic reasons. However, when using three-times the stress activity for rest imaging as recommended by the guidelines, the rest activity will also be reduced by $23 \% .^{37,38}$ Finally, this study was performed on a CZT-based camera instead of a more commonly used conventional Anger camera. However, as demonstrated in our previous studies, we can assume that introduction of patient-specific activity or scan-time protocols as derived for conventional SPECT cameras may allow radiation dose reductions without affecting diagnostic outcomes in these cameras as well. ${ }^{12,39}$

\section{NEW KNOWLEDGE GAINED}

We demonstrated that the use of a low-activity patient-specific protocol did not affect the percentage of scans interpreted as normal or prognostic value in comparison to using a fixed-activity protocol. Although adopting this minimal activity protocol with limited scan time results in a $23 \%$ radiation dose reduction, it is safe to assume that it does not affect diagnostic outcomes and can therefore safely be adopted in clinical practice.

\section{CONCLUSION}

Introduction of a patient-specific low-activity protocol does not affect the percentage of scans interpreted as normal or prognosis. Moreover, application of 2.25 MBq.kg ${ }^{-1}$ Tc-99m Tetrofosmin lowered the mean radiation dose by $23 \%$ to $1.1 \mathrm{mSv}$ for stress CZT-SPECT in comparison to a standard fixed-activity protocol.

\section{Disclosures}

None of the authors have anything to disclose.

\section{Open Access}

This article is distributed under the terms of the Creative Commons Attribution 4.0 International License (http://creative commons.org/licenses/by/4.0/), which permits unrestricted use, distribution, and reproduction in any medium, provided you give appropriate credit to the original author(s) and the source, provide a link to the Creative Commons license, and indicate if changes were made.

\section{References}

1. Flotats A, Knuuti J, Gutberlet M, Marcassa C, Bengel FM, Kaufmann PA, et al. Hybrid cardiac imaging: SPECT/CT and PET/CT. A joint position statement by the European Association of Nuclear Medicine (EANM), the European Society of Cardiac Radiology (ESCR) and the European Council of Nuclear Cardiology (ECNC). Eur J Nucl Med Mol Imaging 2011;38:201-12.

2. Hendel RC, Berman DS, Di Carli MF, Heidenreich PA, Henkin RE, Pellikka PA, et al. ACCF/ASNC/ACR/AHA/ASE/SCCT/ SCMR/SNM 2009 appropriate use criteria for cardiac radionuclide imaging. J Am Coll Cardiol 2009;53:2201-29.

3. National Council on Radiation Protection and Measurements. Ionizing radiation exposure of the population of the United States. Report no. 160. Bethesda, MD: National Council on Radiation Protection and Measurements; 2009. 
4. Mercuri M, Pascual TNB, Mahmarian JJ, Shaw LJ, Dondi M, Paez $\mathrm{D}$, et al. Estimating the reduction in the radiation burden from nuclear cardiology through use of stress-only imaging in the United States and worldwide. JAMA Intern Med 2016;176:26973.

5. van Dijk JD, Mouden M, Ottervanger JP, van Dalen JA, Knollema $\mathrm{S}$, Slump $\mathrm{CH}$, et al. Value of attenuation correction in stress-only myocardial perfusion imaging using CZT-SPECT. J Nucl Cardiol 2017;24:395-401. doi:10.1007/s12350-015-0374-2.

6. Heller GV, Bateman TM, Johnson LL, Cullom SJ, Case JA, Galt JR, et al. Clinical value of attenuation correction in stress-only Tc99m sestamibi SPECT imaging. J Nucl Cardiol 2004;11:273-81.

7. Trägårdh E, Valind S, Edenbrandt L. Adding attenuation corrected images in myocardial perfusion imaging reduces the need for a rest study. BMC Med Imaging 2013;13:14-9.

8. Duvall WL, Guma KA, Kamen J, Croft LB, Parides M, George T, et al. Reduction in occupational and patient radiation exposure from myocardial perfusion imaging: Impact of stress-only imaging and high-efficiency SPECT camera technology. J Nucl Med 2013;54:1251-7.

9. Henzlova MJ, Duvall WL. The future of SPECT MPI: Time and dose reduction. J Nucl Cardiol 2011;18:580-7.

10. Nakazato R, Berman DS, Hayes SW, Fish M, Padgett R, Xu Y, et al. Myocardial perfusion imaging with a solid-state camera: Simulation of a very low dose imaging protocol. J Nucl Med 2013;54:373-9.

11. van Dijk JD, Jager PL, Mouden M, Slump CH, Ottervanger JP, de Boer J, et al. Development and validation of a patient-tailored dose regime in myocardial perfusion imaging using CZT-SPECT. J Nucl Cardiol 2014;21:1158-67.

12. van Dijk JD, Jager PL, Ottervanger JP, de Boer J, Oostdijk AHJ, Engbers EM, et al. Development and validation of a patient-tailored dose regime in myocardial perfusion imaging using conventional SPECT. J Nucl Cardiol 2016;23:134-42.

13. van Dijk JD, Jager PL, Ottervanger JP, Slump CH, de Boer J, Oostdijk AHJ, et al. Minimizing patient-specific tracer dose in myocardial perfusion imaging using CZT SPECT. J Nucl Med Technol 2015;43:36-40.

14. Mouden M, Timmer JR, Ottervanger JP, Reiffers S, Oostdijk AHJ, Knollema S, et al. Impact of a new ultrafast CZT SPECT camera for myocardial perfusion imaging: Fewer equivocal results and lower radiation dose. Eur J Nucl Med Mol Imaging 2012;39:104855.

15. Oddstig J, Hedeer F, Jögi J, Carlsson M, Hindorf C, Engblom H. Reduced administered activity, reduced acquisition time, and preserved image quality for the new CZT camera. J Nucl Cardiol 2013;20:38-44.

16. Agatston AS, Janowitz WR, Hildner FJ, Zusmer NR, Viamonte M, Detrano R. Quantification of coronary artery calcium using ultrafast computed tomography. J Am Coll Cardiol 1990;15:827-32.

17. Andersson M, Johansson L, Minarik D, Leide-svegborn S, Mattsson S. Effective dose to adult patients from 338 radiopharmaceuticals estimated using ICRP biokinetic data, ICRP/ICRU computational reference phantoms and ICRP 2007 tissue weighting factors. EJNMMI Phys 2014;1:13.

18. Berman DS, Hachamovitch R, Kiat H, Cohen I, Cabico JA, Wang $\mathrm{FP}$, et al. Incremental value of prognostic testing in patients with known or suspected ischemic heart disease: A basis for optimal utilization of exercise technetium-99m sestamibi myocardial perfusion single-photon emission computed tomography. J Am Coll Cardiol 1995;26:639-47.

19. Thygesen K, Alpert JS, Jaffe AS, Simoons ML, Chaitman BR, White HD, et al. Third universal definition of myocardial infarction. J Am Coll Cardiol 2012;60:1581-98.
20. Duvall WL, Sweeny JM, Croft LB, Ginsberg E, Guma KA, Henzlova MJ. Reduced stress dose with rapid acquisition CZT SPECT MPI in a non-obese clinical population: Comparison to coronary angiography. J Nucl Cardiol 2012;19:19-27.

21. Einstein AJ, Blankstein R, Andrews H, Fish M, Padgett R, Hayes $\mathrm{SW}$, et al. Comparison of image quality, myocardial perfusion, and left ventricular function between standard imaging and single-injection ultra-low-dose imaging using a high-efficiency SPECT camera: The MILLISIEVERT study. J Nucl Med 2014;55:1430-7.

22. Palyo RJ, Sinusas AJ, Liu Y-H. High-sensitivity and high-resolution SPECT/CT systems provide substantial dose reduction without compromising quantitative precision for assessment of myocardial perfusion and function. J Nucl Med 2016;57:893-9.

23. Herzog BA, Buechel RR, Katz R, Brueckner M, Husmann L, Burger IA, et al. Nuclear myocardial perfusion imaging with a cadmium-zinc-telluride detector technique: Optimized protocol for scan time reduction. J Nucl Med 2010;51:46-51.

24. Esteves FP, Raggi P, Folks RD, Keidar Z, Askew JW, Rispler S, et al. Novel solid-state-detector dedicated cardiac camera for fast myocardial perfusion imaging: Multicenter comparison with standard dual detector cameras. J Nucl Cardiol 2009;16:927-34.

25. Buechel RR, Herzog BA, Husmann L, Burger IA, Pazhenkottil $\mathrm{AP}$, Treyer $\mathrm{V}$, et al. Ultrafast nuclear myocardial perfusion imaging on a new gamma camera with semiconductor detector technique: First clinical validation. Eur J Nucl Med Mol Imaging 2010;37:773-8.

26. Duvall WL, Croft LB, Godiwala T, Ginsberg E, George T, Henzlova MJ. Reduced isotope dose with rapid SPECT MPI imaging: Initial experience with a CZT SPECT camera. J Nucl Cardiol 2010;17:1009-14.

27. Duvall WL, Croft LB, Ginsberg ES, Einstein AJ, Guma KA, George $\mathrm{T}$, et al. Reduced isotope dose and imaging time with a high-efficiency CZT SPECT camera. J Nucl Cardiol 2011;18:84757.

28. Einstein AJ, Johnson LL, DeLuca AJ, Kontak AC, Groves DW, Stant $\mathrm{J}$, et al. Radiation dose and prognosis of ultra-low-dose stress-first myocardial perfusion SPECT in patients with chest pain using a high-efficiency camera. J Nucl Med 2015;56:545-51.

29. Songy B, Lussato D, Guernou M, Queneau M, Geronazzo R. Comparison of myocardial perfusion imaging using Thallium-201 between a new cadmium-zinc-telluride cardiac camera and a conventional SPECT camera. Clin Nucl Med 2011;36:776-80.

30. Chowdhury FU, Vaidyanathan S, Bould M, Marsh J, Trickett C, Dodds $\mathrm{K}$, et al. Rapid-acquisition myocardial perfusion scintigraphy (MPS) on a novel gamma camera using multipinhole collimation and miniaturized cadmium-zinc-telluride (CZT) detectors: Prognostic value and diagnostic accuracy in a "realworld" nuclear cardiology service. Eur Heart J Cardiovasc Imaging 2014;15:275-83.

31. Yokota S, Mouden M, Ottervanger JP, Engbers E, Knollema S, Timmer JR, et al. Prognostic value of normal stress-only myocardial perfusion imaging: A comparison between conventional and CZT-based SPECT. Eur J Nucl Med Mol Imaging 2016;43:296-301.

32. Edenbrandt L, Ohlsson M, Trägårdh E, Hachamovitch R, Berman $\mathrm{D}$, Kiat $\mathrm{H}$, et al. Prognosis of patients without perfusion defects with and without rest study in myocardial perfusion scintigraphy. EJNMMI Res 2013;3:58-67.

33. Mathur S, Heller GV, Bateman TM, Ruffin R, Yekta A, Katten D, et al. Clinical value of stress-only Tc-99m SPECT imaging: Importance of attenuation correction. J Nucl Cardiol 2013;20:2737.

34. Ferreira MJV, Cunha MJ, Albuquerque A, Moreira AP, Ramos D, Costa G, et al. Prognosis of normal stress-only gated-SPECT 
myocardial perfusion imaging: A single center study. Int J Cardiovasc Imaging 2013;29:1639-44.

35. Ueyama T, Takehana K, Maeba H, Iwasaka T. Prognostic value of normal stress-only technetium-99 m myocardial perfusion imaging protocol-Comparison with standard stress-rest protocol. Circ J 2012;76:2386-91.

36. van Dijk JD, van Dalen JA, Mouden M, Ottervanger JP, Knollema $\mathrm{S}$, Slump $\mathrm{CH}$, et al. Value of automatic patient motion detection and correction in myocardial perfusion imaging using a CZTbased SPECT camera. J Nucl Cardiol 2016. doi:10.1007/s12350016-0571-7.
37. Verberne HJ, Acampa W, Anagnostopoulos C, Ballinger J, Bengel $\mathrm{F}$, De Bondt $\mathrm{P}$, et al. EANM procedural guidelines for radionuclide myocardial perfusion imaging with SPECT and SPECT/CT: 2015 revision. Eur J Nucl Med Mol Imaging 2015;42:1929-40.

38. Henzlova MJ, Duvall WL, Einstein AJ, Travin MI, Verberne HJ. Erratum to: ASNC imaging guidelines for SPECT nuclear cardiology procedures: Stress, protocols, and tracers. J Nucl Cardiol 2016;23:640-2.

39. van Dijk JD, Jager PL, Ottervanger JP, Slump CH, Knollema S, van Dalen JA. Patient-specific tracer activity in MPI SPECT: A hands-on approach. J Nucl Cardiol 2016;23:145-8. 